\title{
Nonlinear Creep Model for Deep Rock under High Stress and High Pore Water Pressure Condition
}

\author{
Xie Yuanguang ${ }^{1}$, Jiang Haifei ${ }^{{ }^{*}}, \mathrm{Li} \mathrm{Jie}^{1}$ and Xue Kaixi ${ }^{2,3}$ \\ ${ }^{1}$ International College, Chongqing Jiaotong University, Chongqing 400074, China \\ ${ }^{2}$ Civil \& Architecture Engineering Department, East China University of Technology, Nanchang, Jiangxi, 330013, China \\ ${ }^{3}$ Civil and Environmental Engineering Department, College of Engineering and Computer Science, California State University, Fullerton, \\ 800 N. State College Blvd, CA92834, United States
}

Received 23 November 2015; Accepted 13 May 2016

\begin{abstract}
Conventional triaxial compression creep experiments for deep sandstone under high confining pressure and high pore water pressure were carried out, in order to predict the creep response of deep rock under these conditions. A nonlinear viscoelastic-plastic creep constitutive model was proposed based on the experimental results. The theory of component model was used as a basis for the formulation of this model. First, by using mathematical fitting and analogy, a new nonlinear viscous component was introduced based on the properties of the creep curves during the tertiary stage. Second, a timer component to judge whether the creep can get into the tertiary stage was presented. Finally, a nonlinear creep model was proposed. Results showed good agreement between theory curves from the nonlinear creep model and experimental data. This model can be applied to predict deep rock creep responses under high stress and high pore water pressure conditions. Hence, the obtained conclusions in this study are beneficial to deep rock engineering.
\end{abstract}

Keywords: deep rock, triaxial compression, high stress, pore water pressure, creep model, model identification

\section{Introduction}

The growing demand for energy and the heightened intensity of mining activities throughout the world have resulted in an increasing number of mines resorting to deep mining. The geologic environment in a deep rock mass may be complex, and many engineering accidents in the excavation can be encountered. Thus, the problems of large deformations in surrounding rock caused by high stress and high water pressure has received increasing attention from researchers in recent years. Meanwhile, creep characteristic has been identified as an important factor that can be used to identify deformation failures in surrounding rock and to create effective control engineering designs. Therefore, the deep rock creep properties under high stress and high water pressure have became an important research topic [1]. As mineral explorations go deeper, the possibility of disasters and various risks has increased, making it difficult to excavate and support underground excavations. Moreover, high stress and high water pressure in deep rock mass can deteriorate the performance of the structure and mechanics of the surrounding rock, resulting in increased creep deformation that, in turn, can seriously affect the stability of surrounding rock [2]. Thus, the results of the present study may be of significant value to the stability issues in deep rock engineering under high stress and high pore water pressure conditions.

\section{State of the art}

\footnotetext{
*E-mail address: jhfcivil@cqitu.edu.cn ISSN: 1791-2377 @ 2016 Eastern Macedonia and Thrace Institute of Technology. All rights reserved.
}

Many scholars have investigated the creep properties of rock and proposed their own models and conclusions. For example, Wassmann et al. investigated the rheology of the plate interface dissolution precipitation creep in highpressure metamorphic rocks [3]. Mishra et al. investigated the time-dependent behavior of laminated shale based on triaxial creep test results [4]. Guang et al. carried out the shear creep test of saturated phyllite along the schistosity surface under different stress levels, and then systematically compared the test results with the samples obtained from airdried conditions [5]. Liu et al. performed a series of triaxial compressive creep tests on the Callovo-Oxfordian argillite from the underground research laboratory of Andra at Bure in France, and investigated the effects of deviatoric stress level and structural anisotropy on creep deformation [6]. Chang et al. used geomechanics-based numerical modeling to qualitatively explain the cause and evolution of slope creep behavior; the results showed that the bending type of structures developed near slope surfaces, and that the buckling type of structures can be associated with the deformation or slides of a slope [7]. Jiang et al. carried out a gradated uniaxial direct tensile creep test for fine sandstone by adopting a custom-designed direct tensile test device for rock; they then proposed a new nonlinear viscoelastic-plastic creep model that can describe the properties of attenuation creep, steady creep, and accelerated creep [8]. Liu et al. carried out a step loading triaxial creep test for deep sandstone from a site in Chongqing under high confining pressure and high pore water pressure, and proposed a new nonlinear viscoelastic-plastic constitutive model. Finally, they employed the Matlab programming based on QuastNewton nonlinear optimization algorithm (BFGS) to identify the model parameters [9]. Gabriel et al. proposed a new 
empirical model that comprehends the three creep stages [10]. Hakan et al. proposed a mathematical modeling of the creep behavior of Tuzkoy rock salt based on several creep tests [11]. Xiong et al. studied the effects of water content and anisotropy on the mechanical behavior of green-schist, and analyzed the influences of the geometric relationship between the loading orientation and the bedding plane, water content, and volumetric content of the marble interlayer [12]

Meanwhile, Wang et al. performed triaxial creep tests to investigate the creep behavior of salt rock, and found that the creep of salt rock showed a nonlinear characteristic. Based on these results, they further proposed an improved Maxwell creep model by connecting an elastic body softened over time with a viscosity body hardened over time in series [13]. Wang et al. then established a nonlinear viscoelasto-plastic creep model for rock by connecting the modified fractional viscous body with the traditional elastoplastic bodies in series; the proposed model can well reflect the three stages of the rock creep process [14]. Zhang et al. conducted triaxial creep tests using a rock servo-controlling rheological testing machine, investigated the relationship between axial strain and time under different confining pressures, and analyzed the creep failure mechanisms under different confining pressures. They found that the main failure mechanism of clastic rock is plastic shear, accompanied by a significant compression and ductile dilatancy [15]. Lu et al. proposed a physically-motivated dual-scale modeling approach to model the time-dependent damage, deformation and fracturing behavior of heterogeneous brittle rocks during creep. Their proposed model used a microcrack-based damage constitutive law established at the elemental scale, in which the time-dependent degradation of elastic stiffness and damage-induced anisotropy are directly linked to microcrack growth [16]. In another study, Liu et al. performed creep experiments on the deep saturated rock from Dongguanshan Mine by employing uniaxial singlestage loading and graded incremental cyclic loading. They found that the creep curves are very smooth under low stress, but the phenomena of wave and catastrophe turn up under high stress; moreover, the bearing capacity of rock weakens over time [17]. Despite these works, only a few studies have proposed a creep model of deep rock under high stress and high pore water pressure conditions.

The remainder of this paper is organized into sections. Section 3 describes the experimental equipment and procedures. Section 4 makes a combined experimental and theoretical effort to explore a creep model for rock under high stress and high pore water pressure conditions. The model parameters were identified utilizing the First Optimization software (1stOpt). Comparisons between the simulations and experimental data are provided in this section. Finally, the conclusions are summarized in Section 5 .

\section{Methodology}

\subsection{Experimental equipment}

Triaxial creep tests for rock under high stress and high pore water pressure were carried out by using the rock servocontrolled triaxial rheology equipment (RLW-2000, Fig. 1), which was developed by the State Key Laboratory of Coal Mine Disaster Dynamics and Control at Chongqing University, China. The main component of this equipment is a self-equilibrium triaxial pressure system, which consists of three high-precision pumps that control axial pressure, confining pressure, and pore water pressure, respectively. The computerized operations of this equipment ensured that the controlled tests are performed in a safe, timely, and precise manner.

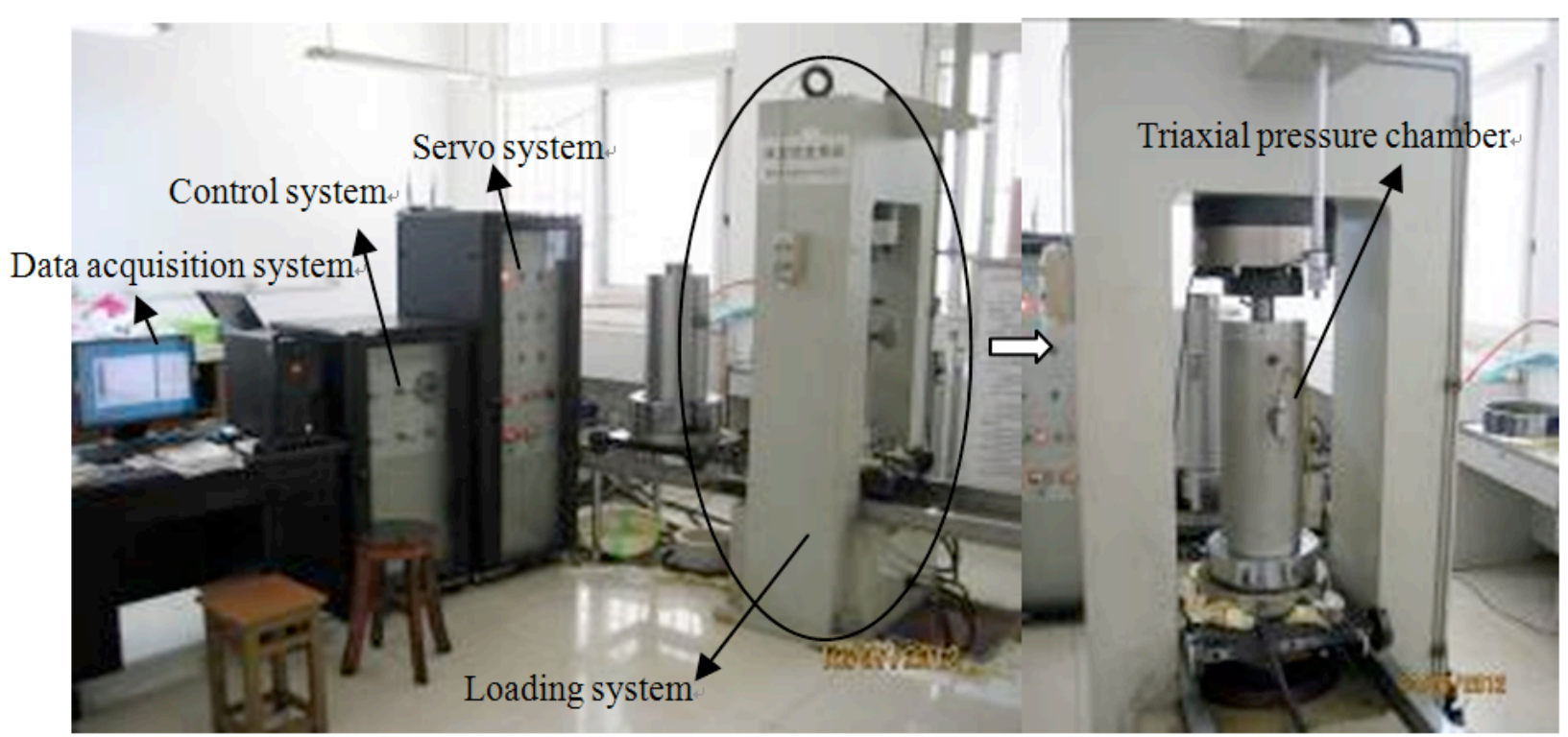

Fig. 1. Rock servo-controlled triaxial rheology equipment

\subsection{Experimental procedures}

The rock sample used for testing was a deep sandstone obtained from the deep mining site in Chongqing. This sample is mainly comprised of quartz, feldspar, flint, and muscovite. The dry density was $2.48-2.83 \mathrm{~g} / \mathrm{cm}^{3}$, porosity $0.58-0.61 \%$, grain diameter $0.01-0.5 \mathrm{~mm}$. The uniaxial compressive strength, elasticity modulus, and Poisson ratio were $72.34 \mathrm{MPa}, 28.16 \mathrm{GPa}$ and 0.15 , respectively.

The deep sandstone samples were transformed into many cylindrical specimens, which were used in the laboratory test. Cylindrical samples of $50 \mathrm{~mm}$ diameter and $100 \mathrm{~mm}$ height were processed in accordance with the International Society for Rock Mechanics (ISRM) testing regulations. 
In order to study the creep properties of rock under high stress and high pore water pressure conditions, the rock saturation tests were performed before the creep tests. The creep experiment procedures are described below.

(1) The saturated specimen (wrapped with flexible membrane) was installed in the test chamber with two linear variable displacement transducer (LVDT) sensors (Fig. 2).

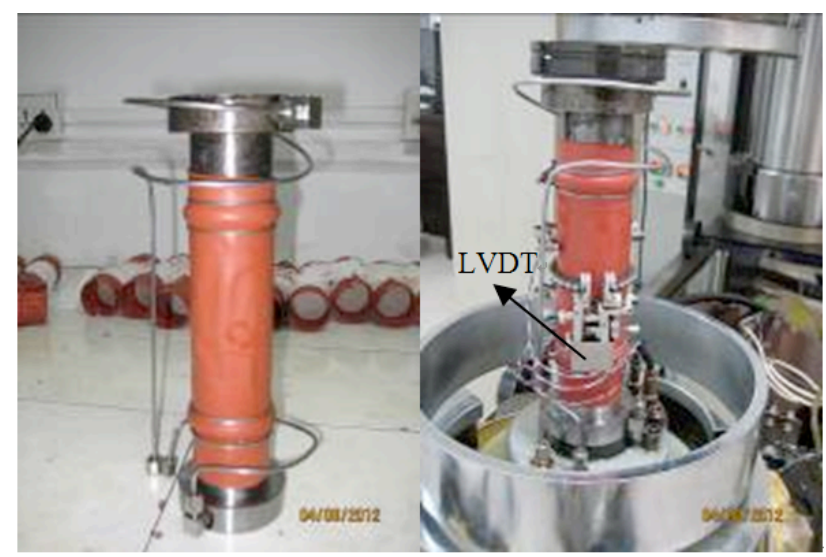

Fig. 2. Specimen wrapped with flexible membrane

(2) The confining pressure was applied at a rate of 1.5 $\mathrm{MPa} / \mathrm{min}$ until the required hydrostatic state was achieved.

(3) After reaching the predefined confining pressure, the deviatoric stress was applied using the stepwise loading method. Then, the pore water pressure was loaded at the set point.

(4) When the rock specimen was loaded to the first stress level at a constant rate of $1.5 \mathrm{MPa} / \mathrm{min}$, the axial stress was kept at a constant value while the automatic data acquisition system recorded information on deformation, confining pressure, and stress level over time.

(5) After completing the creep test under the first stress level, the rock specimen was gradually tested under the succeeding stress levels. Under the last stress level, accelerated creep damage occurred, and variations of the mechanical parameters of rock specimen with time were measured.

\section{Results and discussion}

\subsection{Triaxial creep test results}

For three sandstone specimens, the triaxial creep tests were performed under confining pressure of $40 \mathrm{MPa}$ with pore water pressures of 5, 10 and $15 \mathrm{MPa}$, respectively. During the creep tests, pre-determined multi-step stress levels (Tab. 1) were applied in steps under the specific confining pressure and pore water pressure.

Prior to conducting the triaxial creep tests, short-term strength tests were first conducted, in order to determine the stress level in the triaxial creep test. The average yield stress values are shown in Tab. 1

Table 1. Pre-confirmed stress levels of specimens before the creep tests according to short-term strengths

\begin{tabular}{|c|c|c|c|c|c|c|c|c|c|}
\hline \multirow{2}{*}{$\begin{array}{c}\text { Specimen } \\
\text { No. } \\
\text { I }\end{array}$} & \multirow{2}{*}{$\begin{array}{c}\begin{array}{c}\text { Confining pressure } \\
\text { /MPa }\end{array} \\
40\end{array}$} & \multirow{2}{*}{$\begin{array}{c}\begin{array}{c}\text { Pore water } \\
\text { pressure } \\
\text { /MPa }\end{array} \\
5\end{array}$} & \multirow{2}{*}{$\begin{array}{c}\begin{array}{c}\text { Yield strengt } \\
\text { /MPa }\end{array} \\
199.35\end{array}$} & \multicolumn{6}{|c|}{ Deviatoric stress level/MPa } \\
\hline & & & & 30.57 & 71.34 & 112.10 & 152.87 & 193.63 & 224.20 \\
\hline II & 40 & 10 & 190.76 & 30.57 & 71.34 & 112.10 & 152.87 & 193.63 & - \\
\hline III & 40 & 15 & 179.46 & 30.57 & 71.34 & 112.10 & 152.87 & 193.63 & - \\
\hline
\end{tabular}

Each deviatoric stress level before the final failure in the deviatoric stress level was maintained for no less than $49 \mathrm{~h}$. The creep tests were carried out in five to six stress steps. The triaxial creep experimental results of deep sandstone under high confining pressure and high pore water pressure are shown in Fig. 3, in which the various levels of stress loadings are identified above the curve.

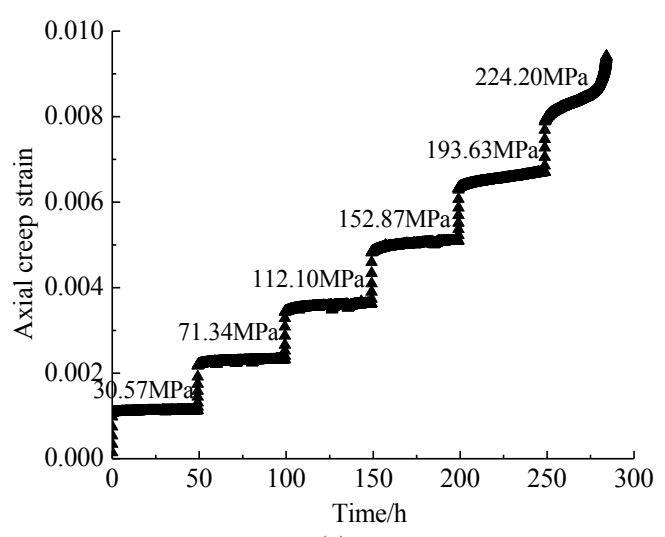

(a)

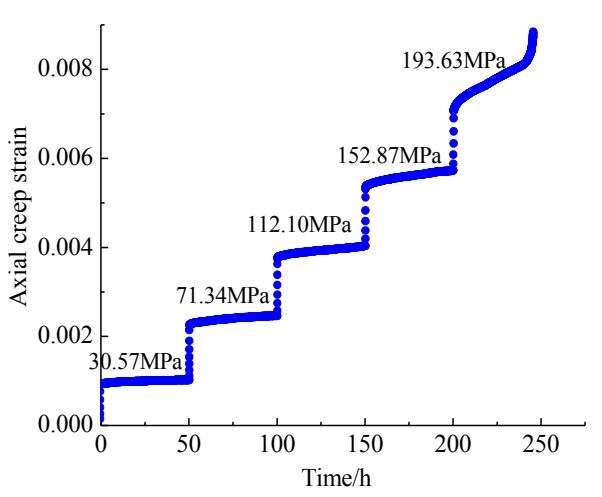

(b)

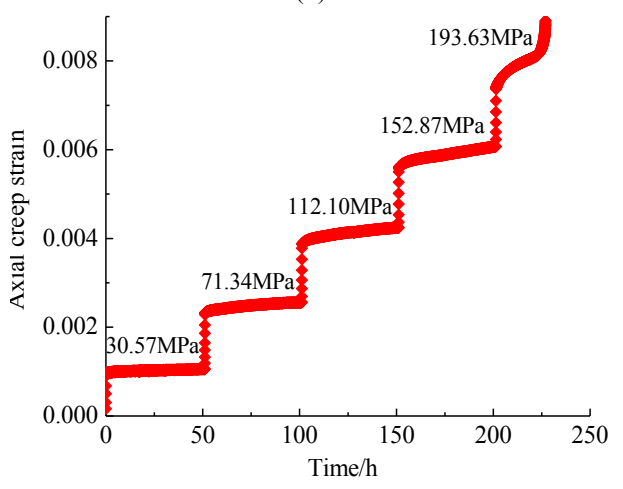


(c)

Fig. 3. Creep curves of sandstone step loading under high confining pressure and high water pressure. (a) specimen I, (b) specimen II, (c) specimen III.

When the applied stress was less than the yield stress, creep curves comprise the period of attenuation and the steady period, which is characterized by the typical linear features. Meanwhile, the accelerated creep begins to appear after the period of attenuation and steady period, along with the typical nonlinear features when the applied stress exceed the yield stress. The traditional component model can well describe the linear creep properties, but it cannot accurately determine the nonlinear creep characteristics [1]. Therefore, presenting a nonlinear model that can describe the nonlinear accelerated creep is necessary.

As shown in Fig. 4, the creep shows mainly the attenuation and steady state before the accelerated creep startup time $t_{f}$, while it moves toward the accelerated creep period after $t_{f}$ with the characteristics of nonlinear creep. This means that the linear viscoplastic creep occurred before the $t_{f}$ when the applied stress is greater than the yield stress. Thus, if the applied stress is beyond the yield stress, it is inapposite to use the nonlinear creep model to describe the whole creep process. For this reason, we can use the linear viscoplastic model to describe the creep before the $t_{f}$, and use nonlinear viscoplastic model to describe the accelerated creep after $t_{f}$.

\subsection{Nonlinear viscous component}

A traditional component creep model cannot be used for describing nonlinear accelerated creep during the tertiary stage. Meanwhile, accelerated creep under high stress is the main factor that induces rock failure. Thus, it is necessary to study the nonlinear creep properties and acquire a nonlinear creep model, which can describe the nonlinear accelerated creep during the tertiary stage. In order to establish a nonlinear creep model, we can replace the linear viscous component with a nonlinear one in the component creep model.

Empirical equation was adopted to fit the experimental data during the tertiary stage; a nonlinear viscosity coefficient $\left(\eta_{(n, t)}\right)$ that varied with time was obtained by using the analogy method and then a nonlinear viscous component was presented.

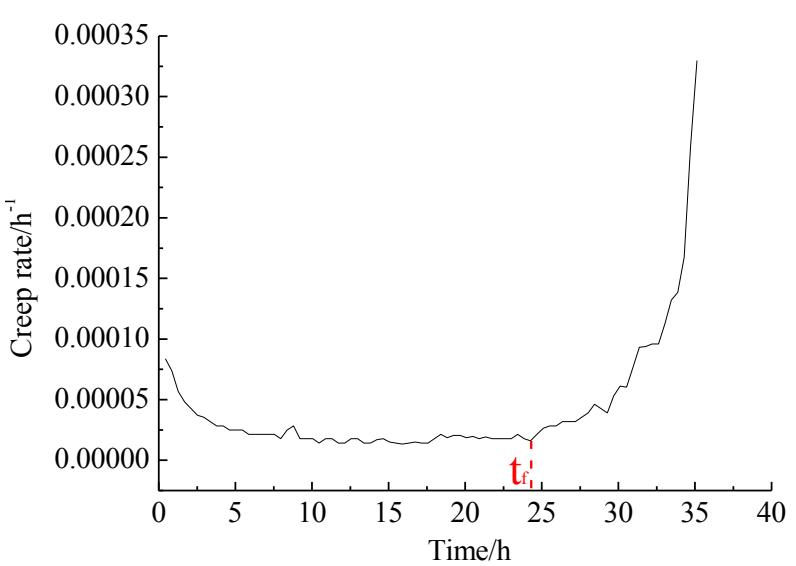

(a)

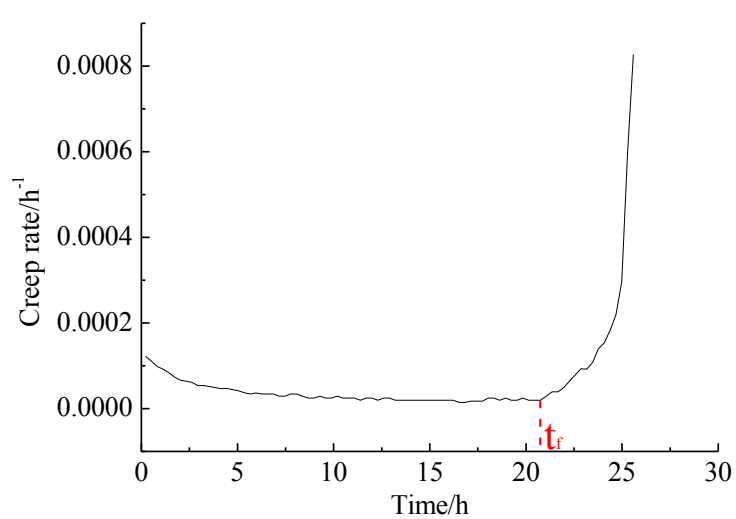

(b)

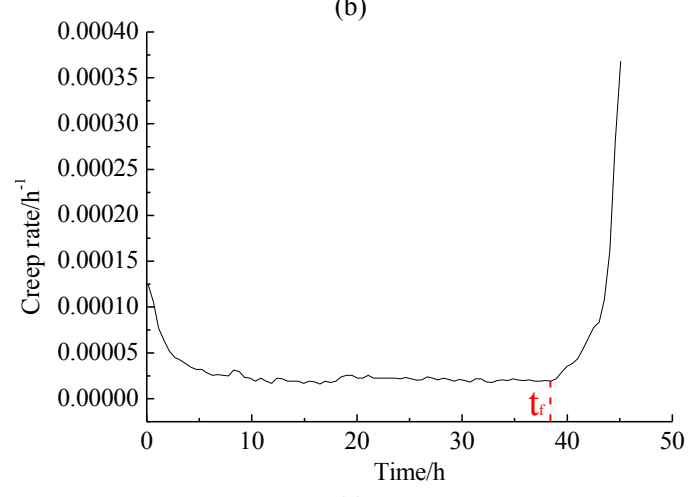

(c)

Fig. 4. The relation curves of creep rate and creep time. (a) specimen I, (b) specimen II, (c) specimen III

The fitting parameters of the accelerated creep portion for specimens I, II, and, III based on Eq. (1) are listed in Tab. 2. The comparison between fitting curves and test curves is shown in Fig. 5. From the values of $R^{2}$ listed in Tab. 2, we can observe that the fitting results of the direct tensile accelerated creep portion of the curves in Fig. 5 using Eq. (1) are relatively good.

Table 2. Fitting results of the accelerated creep portion for specimens I, II, and III based on Eq. (1).

\begin{tabular}{ccccc}
\hline Specimen No. & $\varepsilon_{0}$ & $A$ & $n$ & $R^{2}$ \\
\hline I & 0.0084 & $1.5095 \mathrm{E}-7$ & 0.2456 & 0.9972 \\
II & 0.0080 & $1.2148 \mathrm{E}-18$ & 0.4441 & 0.9911 \\
III & 0.0084 & $4.2926 \mathrm{E}-12$ & 0.7411 & 0.9887 \\
\hline
\end{tabular}

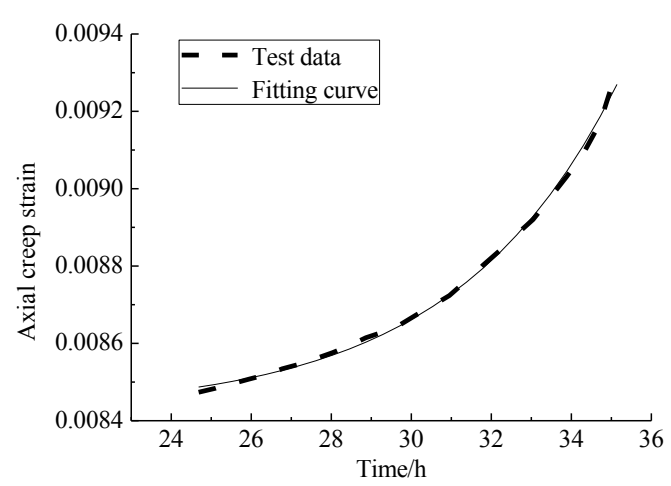

(a) 


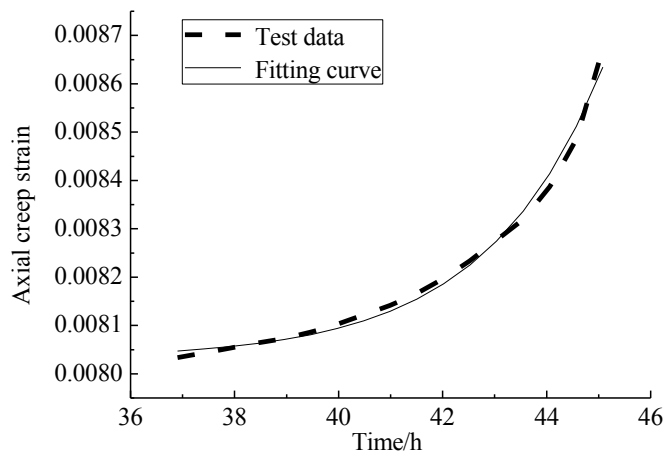

(b)

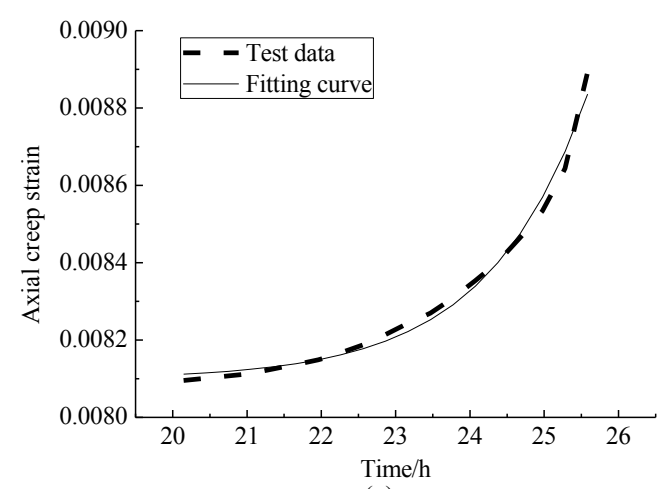

(c)

Fig. 5. Comparison between fitting curves and test data. (a) specimen I, (b) specimen II, (c) specimen III

The creep equation of linear component is given by

$$
\varepsilon=\frac{\sigma t}{\eta}+C
$$

By using the analogy method, we can make Eq. (1) equal to Eq. (2), i.e., $A=\frac{\sigma}{\eta_{0}}, C=\varepsilon_{0}$, thus, the nonlinear expression of $\eta$ can be obtained by using

$$
\eta_{(n, t)}=\frac{\eta_{0} t / t_{0}}{e^{n t / t_{0}}}=\frac{\eta_{0} t}{e^{n t}}
$$

Where $t_{0}$ is the reference time with the value of $1, \eta_{0}$ is initial accelerated creep viscous value, and $n$ is accelerated index.

A nonlinear viscous component was thus obtained by assuming that the viscosity coefficient of a dashpot element fit the formulation given by Eq. (3), as shown in Fig. 6.

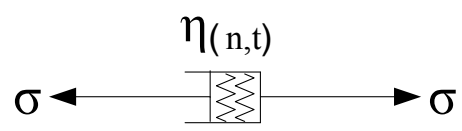

Fig. 6. Nonlinear viscous component

\subsection{Nonlinear viscoelastic-plastic creep model}

Some studies have indicated that the starting time of accelerated creep has significant difference at the stage of rock failure in different stress states. Given that rock creep shows linear features at the stable creep stage, but nonlinear features at the accelerated stage, the selection of nonlinear equation to describe the whole creep process makes it difficult to accurately identify the creep parameters. To enable the extension of the nonlinear creep model, namely, having the ability to describe the accelerated creep characteristic in different conditions, it may be necessary to introduce the startup time of accelerated creep into the creep model, as mentioned in Section 1.

The startup time of accelerated creep $t_{f}$ was defined as the critical time point of the transition from stable creep to accelerated creep. A new nonlinear viscoplastic creep model was obtained (Fig. 7) by introducing the starting time of accelerated creep into the creep model.

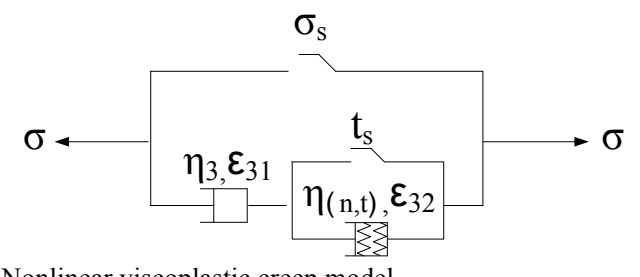

Fig. 7. Nonlinear viscoplastic creep model

This model can reflect both linear viscoplastic creep before startup time and nonlinear viscoplastic creep after startup time when the applied stress exceeds the yield stress. With applied constant stress $\sigma$, the corresponding creep equation to the nonlinear viscoplastic creep model is given by

$\varepsilon_{(t)}=\frac{H_{1}\left(\sigma-\sigma_{s}\right)}{\eta_{3}} t+\frac{H_{1}\left(\sigma-\sigma_{s}\right)}{\eta_{(n, t)}} H_{2}\left(t-t_{f}\right)$
$=\frac{H_{1}\left(\sigma-\sigma_{s}\right)}{\eta_{3}} t+\frac{H\left(\sigma-\sigma_{s}\right)}{\eta_{0}\left(t-t_{f}\right)} H_{2}\left(t-t_{f}\right) e^{n\left(t-t_{f}\right)}$

where $\sigma_{s}$ is the yield stress, $t_{s}$ is the starting time of accelerated creep, and $\eta_{3}$ is the linear viscous coefficient expressed as

$H_{1}\left(\sigma-\sigma_{s}\right)=\left\{\begin{array}{cl}0 & \left(\sigma<\sigma_{S}\right) \\ \sigma-\sigma_{s} & \left(\sigma \geq \sigma_{S}\right)\end{array}, H_{2}\left(t-t_{S}\right)=\left\{\begin{array}{cc}0 & \left(t<t_{f}\right) \\ t-t_{f} & \left(t \geq t_{f}\right)\end{array}\right.\right.$

A series combination of this nonlinear viscoplastic creep model and the Burgers creep model is presented to obtain a new nonlinear viscoelastic-plastic creep model (Fig. 8).

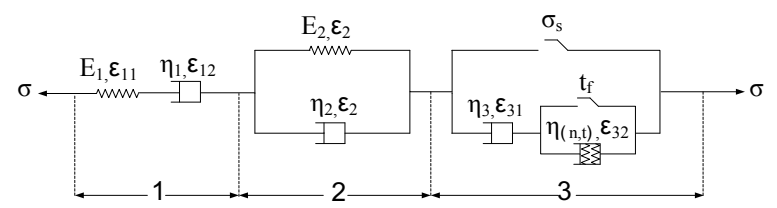

Fig. 8. Nonlinear viscoelasto-plastic creep model.

(1 denotes the Mexwell model, 2 denotes the Kelvin model, and 3 denotes denotes the nonlinear viscoplastic model proposed in this paper; the Burgers model comprises the Kelvin model and Mexwell models. )

The corresponding state equation is given by 
$\sigma=\sigma_{1}=\sigma_{2}=\sigma_{3}, \quad \sigma_{2}=E_{2} \cdot \varepsilon_{2}+\eta_{2} \cdot \varepsilon_{2}$

$\varepsilon=\varepsilon_{1}+\varepsilon_{2}+\varepsilon_{3}, \quad \varepsilon_{1}=\varepsilon_{11}+\varepsilon_{12}=\sigma / E_{1}+\sigma / \eta_{1}$

$\varepsilon_{3}=\frac{H_{1}\left(\sigma-\sigma_{s}\right)}{\eta_{3}} \cdot t+\frac{H\left(\sigma-\sigma_{s}\right)}{\eta_{0} \cdot\left(t-t_{f}\right)} \cdot H_{2}\left(t-t_{f}\right) \cdot e^{n\left(t-t_{f}\right)}$

The above formula is arranged to obtain the corresponding constitutive equation as described below.

(1) If $\sigma<\sigma_{S}$, the model is characterized by linear viscoelastic creep and is transformed into the Burgers model. The corresponding constitutive equation is given by

$\varepsilon=\frac{\sigma_{0}}{E_{1}}+\frac{\sigma_{0}}{\eta_{1}} t+\frac{\sigma_{0}}{E_{2}}\left[1-\exp \left(-\frac{E_{2}}{\eta_{2}} t\right)\right]$

(2) If $\sigma \geq \sigma_{s}, t<t_{f}$, the model is characterized by the linear viscoplastic creep of rock, with the corresponding constitutive equation expressed as

$$
\frac{\eta_{2}}{E_{1}} \sigma+\left(1+\frac{E_{2}}{E_{1}}+\frac{\eta_{2}}{\eta_{1}}+\frac{\eta_{2}}{\eta_{3}}\right) \sigma+\frac{E_{2}}{\eta_{1}} \sigma+\frac{E_{2}}{\eta_{3}}\left(\sigma-\sigma_{S}\right)=E_{2} \varepsilon+\eta_{2} \varepsilon
$$

(3) If $\sigma \geq \sigma_{s}, t \geq t_{f}$, the model is characterized by the nonlinear viscoplastic creep of rock, with the corresponding constitutive equation given by

$$
\begin{aligned}
& \left(\frac{\eta_{2}}{E_{1}}+\frac{\eta_{2} e^{n\left(t-t_{f}\right)}}{\eta_{0}}\right) \sigma+\left(1+\frac{E_{2}}{E_{1}}+\frac{E_{2} e^{n\left(t-t_{f}\right)}}{\eta_{0}}+\frac{\eta_{2}}{\eta_{1}}+\frac{\eta_{2}}{\eta_{3}}+\frac{2 n \eta_{2} e^{n\left(t-t_{f}\right)}}{\eta_{0}}\right) \sigma+ \\
& \left(\frac{E_{2}}{\eta_{3}}+\frac{n E_{2} e^{n\left(t-t_{f}\right)}}{\eta_{0}}+\frac{n^{2} \eta_{2} e^{n\left(t-t_{f}\right)}}{\eta_{0}}\right)\left(\sigma-\sigma_{S}\right)+\frac{E_{2}}{\eta_{1}} \sigma=E_{2} \varepsilon+\eta_{2} \varepsilon
\end{aligned}
$$

By setting $\sigma$ in Eqs. (7) and (8) to be equal to $\sigma_{0}$, which is a constant, these two differential equations are solved to obtain the creep equation given by

$$
\begin{aligned}
& \mathcal{E}=\frac{\sigma_{0}}{E_{1}}+\frac{\sigma_{0}}{\eta_{1}} t+\frac{\sigma_{0}}{E_{2}}\left[1-\exp \left(-\frac{E_{2}}{\eta_{2}} t\right)\right]+\frac{\sigma_{0}-\sigma_{s}}{\eta_{3}} t, \quad \sigma \geq \sigma_{S}, t<t_{f} \\
& \varepsilon=\frac{\sigma_{0}}{E_{1}}+\frac{\sigma_{0}}{\eta_{1}} t+\frac{\sigma_{0}}{E_{2}}\left[1-\exp \left(-\frac{E_{2}}{\eta_{2}} t\right)\right]+\quad \sigma \geq \sigma_{S}, t \geq t_{f} \\
& \frac{\sigma_{0}-\sigma_{s}}{\eta_{3}} t+\frac{\sigma_{0}-\sigma_{s}}{\eta_{0}} \exp \left[n\left(t-t_{S}\right)\right],
\end{aligned}
$$

4.4 Three-dimensional (3D) nonlinear viscoelastic-plastic creep model

In nature, the rock mass is mostly under the $3 \mathrm{D}$ stress state. Hence, it is necessary to establish a $3 \mathrm{D}$ creep model. Under the hypothesis of isotropy and referring to Hooke's law, the rock mass constitutive relation can be obtained by using

$\left.\begin{array}{l}\sigma_{m}=3 K \boldsymbol{\varepsilon}_{m} \\ \boldsymbol{S}_{b}=2 G \boldsymbol{e}_{i}\end{array}\right\}$

where $\boldsymbol{\sigma}_{m}$ is the spherical stress tensor, $\boldsymbol{S}_{i j}$ is the deviatoric stress tensor, $K$ is the shear modulus, and $G$ is the shear modulus.

On the basis of continuum mechanics, the stress tensor $\sigma_{i j}$ is decomposed into two parts: the mean stress tensor $\sigma_{m}$ and the stress deviator tensor $S_{i j}$. The expression is given by

$$
\sigma_{i j}=S_{i j}+\delta_{i j} \sigma_{m}
$$

In the same way, the strain tensor $\boldsymbol{\varepsilon}_{i j}$ is divided into a mean $\boldsymbol{\varepsilon}_{m}$, which is associated with a change in volume, and a deviatoric part $\boldsymbol{e}_{i j}$, which is associated with a change in shape given by

$$
\boldsymbol{\varepsilon}_{i j}=\boldsymbol{e}_{i j}+\delta_{i j} \varepsilon_{m}
$$

For simplicity, with the assumption that the creep is caused only by the stress deviator tensor $\boldsymbol{S}_{i j}$ [2], we can obtain

$\varepsilon=\frac{\left(\boldsymbol{S}_{i j}\right)_{0}}{2 G_{1}}+\frac{\left(\boldsymbol{S}_{i j}\right)_{0}}{2 \eta_{1}} t+\frac{\left(\boldsymbol{S}_{i j}\right)_{0}}{2 G_{2}}\left[1-\exp \left(-\frac{G_{2}}{\eta_{2}} t\right)\right]$,

$\left(\boldsymbol{S}_{i j}\right)_{0}<\left(\boldsymbol{S}_{i j}\right)_{S}$

$\varepsilon=\frac{\left(\boldsymbol{S}_{i j}\right)_{0}}{2 G_{1}}+\frac{\left(\boldsymbol{S}_{i j}\right)_{0}}{2 \eta_{1}} t+\frac{\left(\boldsymbol{S}_{i j}\right)_{0}}{2 G_{2}}\left[1-\exp \left(-\frac{G_{2}}{\eta_{2}} t\right)\right]+$

$\frac{\left(\boldsymbol{S}_{i j}\right)_{0}-\sigma_{s}}{2 \eta_{3}} t, \quad\left(\boldsymbol{S}_{i j}\right)_{0} \geq\left(\boldsymbol{S}_{i j}\right)_{S}, t<t_{f}$

$\mathcal{E}=\frac{\left(\boldsymbol{S}_{i j}\right)_{0}}{2 G_{1}}+\frac{\left(\boldsymbol{S}_{i j}\right)_{0}}{2 \eta_{1}} t+\frac{\left(\boldsymbol{S}_{i j}\right)_{0}}{2 G_{2}}\left[1-\exp \left(-\frac{G_{2}}{\eta_{2}} t\right)\right]+$
$\frac{\left(\boldsymbol{S}_{i j}\right)_{0}-\left(\boldsymbol{S}_{i j}\right)_{s}}{2 \eta_{3}} t+\frac{\left(\boldsymbol{S}_{i j}\right)_{0}-\left(\boldsymbol{S}_{i j}\right)_{s}}{2 \eta_{0}} \exp \left[n\left(t-t_{S}\right)\right]$,

$\left(\boldsymbol{S}_{i j}\right)_{0} \geq\left(\boldsymbol{S}_{i j}\right)_{S}, t \geq t_{f}$

In the conventional triaxial compression test, $\sigma_{2}=\sigma_{3}, \sigma_{m}=\left(\sigma_{1}+2 \sigma_{3}\right) / 3$, and then the corresponding creep equation is deduced as

$$
\begin{aligned}
& \varepsilon=\frac{\sigma_{1}-\sigma_{3}}{3 G_{1}}+\frac{\sigma_{1}-\sigma_{3}}{3 \eta_{1}} t+\frac{\sigma_{1}-\sigma_{3}}{3 G_{2}}\left[1-\exp \left(-\frac{G_{2}}{\eta_{2}} t\right)\right] \text {, } \\
& \sigma_{1}-\sigma_{3}<\left(\sigma_{1}-\sigma_{3}\right)_{S} \\
& \varepsilon=\frac{\sigma_{1}-\sigma_{3}}{3 G_{1}}+\frac{\sigma_{1}-\sigma_{3}}{3 \eta_{1}} t+\frac{\sigma_{1}-\sigma_{3}}{3 G_{2}}\left[1-\exp \left(-\frac{G_{2}}{\eta_{2}} t\right)\right]+ \\
& \frac{\sigma_{1}-\sigma_{3}-\sigma_{s}}{3 \eta_{3}} t, \quad \sigma_{1}-\sigma_{3} \geq\left(\sigma_{1}-\sigma_{3}\right)_{S}, t<t_{f} \\
& \varepsilon=\frac{\sigma_{1}-\sigma_{3}}{3 G_{1}}+\frac{\sigma_{1}-\sigma_{3}}{3 \eta_{1}} t+\frac{\sigma_{1}-\sigma_{3}}{3 G_{2}}\left[1-\exp \left(-\frac{G_{2}}{\eta_{2}} t\right)\right]+ \\
& \frac{\sigma_{1}-\sigma_{3}-\sigma_{s}}{3 \eta_{3}} t+\frac{\sigma_{1}-\sigma_{3}-\sigma_{s}}{3 \eta_{0}} \exp \left[n\left(t-t_{f}\right)\right] \text {, } \\
& \sigma_{1}-\sigma_{3} \geq\left(\sigma_{1}-\sigma_{3}\right)_{S}, t \geq t_{f}
\end{aligned}
$$

4.5 Model parameter determination and model verification

Given that stepped loading was adopted to carry out the creep test, we can transform the creep curves under stepped loading conditions given in Fig. 1 into those under the 
respective loading conditions shown in Fig. 8. This can be done by utilizing the Boltzmann superposition principle.

The First Optimization software (1stOpt) was adopted to identify the model parameters based on the test results. The core of the software is the Universal Global Optimization, the greatest feature of which is that it alleviates the problems associated with establishing suitable initial values when using an iteration method in the optimization. As such, the user must determine initial parameter values, which are determined randomly by the software, and the optimal solution is obtained through its unique global optimizing calculation [8].

When $\sigma_{1}-\sigma_{3} \leq \sigma_{S}$, Eq. (15-1) was adopted to conduct fitting to the test curves. The related parameters obtained are listed in Tab. 3. The $R^{2}$ values of the fitting results were all greater than 0.92 . When $\sigma_{1}-\sigma_{3}>\sigma_{S}$, the creep curve was divided into two sections, which were identified respectively. When $t<t_{f}$, Eq. (15-2) was adopted to conduct fitting to the test curves, whereas, for $t \geq t_{f}$, the parameters identified from Eq. (15-2), namely, $G_{1}, G_{2}, \eta_{1}, \eta_{2}$ and $\eta_{3}$, were substituted into Eq. (15-3) in order to maintain the consistency of parameters in the same stress level. With this process, we can have the parameters $\eta_{0}$ and $n$, which are different from those in the condition of $t<t_{f}$. The related parameters obtained are listed in Tab. 3. From the $R^{2}$ values of the fitting results, which were all greater than 0.96 , we can say that the model fit the data quite well.

Table 3. Model parameters for deep sandstone samples under high confining pressure and high water pressure

\begin{tabular}{|c|c|c|c|c|c|c|c|c|c|}
\hline $\begin{array}{c}\text { Specimen } \\
\text { No. }\end{array}$ & Stress level & $G_{1} / \mathbf{G P a}$ & $G_{2} / \mathbf{G P a}$ & $\eta_{1} / \mathbf{G P a} \cdot \mathbf{h}$ & $\eta_{2} / \mathbf{G P a} \cdot \mathbf{h}$ & $\eta_{3} / \mathbf{G P a} \bullet \mathbf{h}$ & $\eta_{0} / \mathbf{G P a} \cdot \mathbf{h}$ & $n$ & $R^{2}$ \\
\hline \multirow{6}{*}{$\begin{array}{c}\text { Specimen } \\
\text { I }\end{array}$} & 30.57 & 9.41 & 197.77 & 8.89E5 & 3755.45 & - & - & - & 0.95 \\
\hline & 71.34 & 10.79 & 363.39 & $2.39 \mathrm{E} 4$ & 2616.88 & - & - & - & 0.94 \\
\hline & 112.10 & 10.85 & 528.00 & $1.82 \mathrm{E} 4$ & 3141.67 & - & - & - & 0.94 \\
\hline & 152.87 & 10.55 & 502.02 & $1.37 \mathrm{E} 4$ & 1546.31 & - & - & - & 0.97 \\
\hline & 193.63 & 10.20 & 848.50 & $1.05 \mathrm{E} 4$ & 2416.42 & - & - & - & 0.99 \\
\hline & 224.20 & 8.00 & 223.30 & $1.37 \mathrm{E} 4$ & 7989.13 & 6421.10 & 84.20 & 0.18 & 0.98 \\
\hline \multirow{5}{*}{$\begin{array}{c}\text { Specimen } \\
\text { II }\end{array}$} & 30.57 & 11.25 & 246.73 & 7483.96 & 973.32 & - & - & - & 0.99 \\
\hline & 71.34 & 10.53 & 119.61 & $5.77 \mathrm{E} 4$ & 3389.88 & - & - & - & 0.99 \\
\hline & 112.10 & 10.00 & 446.62 & $1.04 \mathrm{E} 4$ & 2555.12 & - & - & - & 0.99 \\
\hline & 152.87 & 9.48 & 340.29 & $1.34 \mathrm{E} 4$ & 5049.16 & - & - & - & 0.87 \\
\hline & 193.63 & 9.19 & 316.42 & 9470.33 & 75.08 & 74.83. & 396.18 & 0.75 & 0.99 \\
\hline \multirow{5}{*}{$\begin{array}{l}\text { Specimen } \\
\text { III }\end{array}$} & 30.57 & 10.59 & 281.81 & 8591.84 & 798.75 & - & - & - & 0.97 \\
\hline & 71.34 & 10.15 & 154.42 & $1.49 \mathrm{E} 4$ & 2925.66 & - & - & - & 0.99 \\
\hline & 112.10 & 9.62 & 423.39 & 6316.61 & 423.39 & - & - & - & 0.98 \\
\hline & 152.87 & 9.21 & 276.14 & 7027.26 & 354.85 & - & - & - & 0.99 \\
\hline & 193.63 & 8.60 & 169.69 & 3551.10 & 2902.12 & $3.21 \mathrm{E} 8$ & $3.01 \mathrm{E} 4$ & 1.72 & 0.98 \\
\hline
\end{tabular}

Substituting the parameters obtained into the creep equation, we can obtain the theory curves of model fitting. Fig. 9 presents comparisons between the creep test curves and the curves derived from the theoretical model for rock under high stress. Results showed that the two curves were rather identical, which not only demonstrated the optimization capability of the 1 stOpt software, but also proved that the nonlinear viscoelastic-plastic model proposed in the present study can accurately reflect the properties of attenuation creep, steady creep, and accelerated creep for rock under high stress, thereby verifying the robustness of the proposed model.

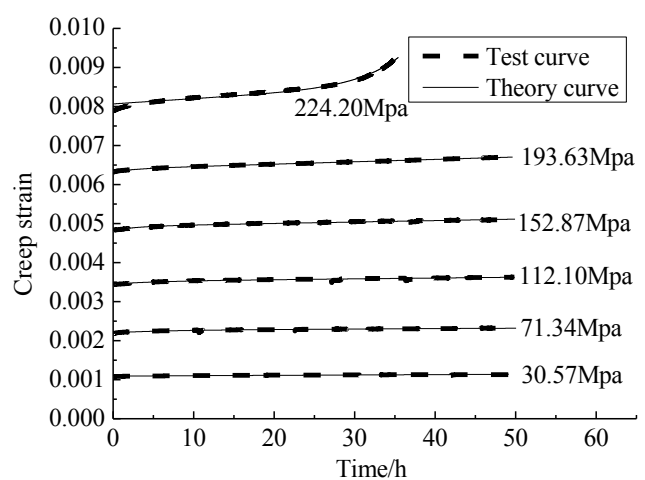

(a)

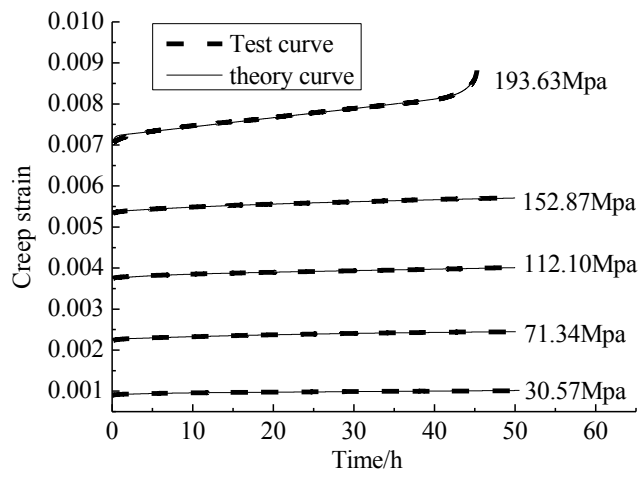

(b)

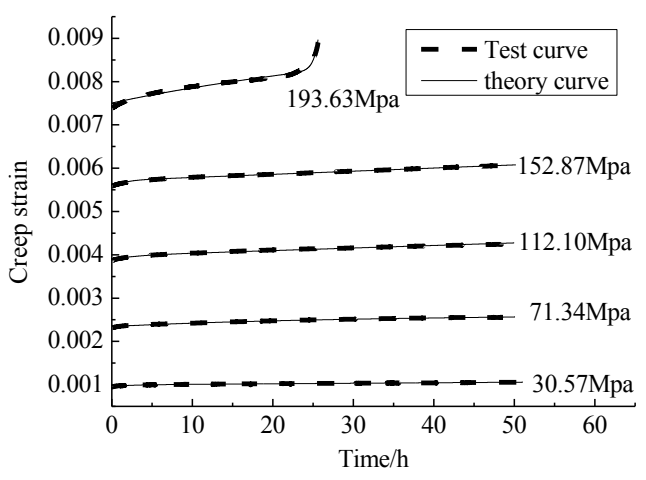

(c)

Fig. 9. Comparison between the theoretical curves and test curves. (a) specimen I. (b) specimen II, (c) specimen III 


\section{Conclusion}

Creep characteristic is now considered an important factor in determining deformation failures in surrounding rock and in coming up with effective control engineering designs. Therefore, studying the creep mechanical properties of deep rock under high stress and high pore water pressure conditions is an urgent task.

In this paper, a nonlinear viscous component was created by using the fitting and analogy the methods by the analysis of the nonlinear creep properties during the tertiary stage. Meanwhile, a timer component judging whether the creep can get into the tertiary stage was introduced. Then, these two components were connected in parallel to form a nonlinear viscoplastic accelerated creep startup model. Next, based on the theory of component model, a new nonlinear viscoelastic-plastic creep constitutive model was proposed, and the $3 \mathrm{D}$ equation of this creep model was deduced. Through the analysis, we find that this model can well describe attenuation creep, steady creep, and the accelerated creep properties of deep rock under high stress and high pore water pressure conditions.
Based on the creep test data, the First Optimization software (1stOpt) was used to identify the model parameters. The results show that the squared correlation coefficients obtained in the fitting process were all greater than 0.94 . The parameter identification was achieved successfully. In addition, a comparison of the test curves with the model curves indicated that they were nearly identical, thus demonstrating that the proposed creep model can accurately describe the creep properties of deep sandstone under high stress and high water pressure conditions.

The results presented in the present study may be of significant value in resolving stability issues of deep rock engineering under high stress and high pore water pressure conditions.

\section{Acknowledgements}

This paper was financially supported by the Chongqing city Fundamental and Advanced Research Projects of China (cstc2015jcyjA90012), Science and technology project of Jiangxi Province (20123BBG70214), and the Doctoral Scientific Research Foundation of Chongqing Jiaotong University (2014kjc II 024).

\section{References}

1. Jiang, H. F., Liu, D. Y., Huang, W., Liu, F. Y., "Influence of high pore water pressure on creep properties of rock under high confining pressure". Journal of the China Coal Society, 39(7),2014, pp.12481256.

2. Jiang, H. F., Liu, D. Y., Huang, W., Xia, Y. C., Liu, F. Y., “Creep properties of rock under high confining pressure and different pore water pressures and a modified Nishihara model". Chinese Journal of Geotechnical Engineering, 36(3), 2014, pp.443-451.

3. Wassmann, S., Stöckhert, B., "Rheology of the plate interface Dissolution precipitation creep in high pressure metamorphic rocks". Tectonophysics, 608, 2013, pp.1-29.

4. Mishra, B., Verma, P., "Uniaxial and triaxial single and multistage creep tests on coal-measure shale rocks". International Journal of Coal Geology, 137, 2015, pp.55-65.

5. Guang, M., R., Xin, L., M., Bo, W., R., Min, X., "The research of shear creep behaviors of saturated sericite-quartz phyllite". Engineering Geology for Society and Territory, 6, 2014, pp.875-880.

6. Liu, Z. B., Xie, S. Y., Shao, J. F., Conil, N., "Effects of deviatoric stress and structural anisotropy on compressive creep behavior of a clayey rock". Applied Clay Science, 114, 2015, pp.491-496.

7. Chang, K. T., Ge, C. L., Lin, H. H., "Slope creep behavior: observations and simulations". Environmental Earth Science, 73(1), 2015, pp.275-287.

8. Jiang, H. F., Xie, Y. G., Zhao, B. Y., Xue, K. X., "The creep properties of fine sandstone under uniaxial tensile stress". Journal of Engineering Science and Technology Review, 8(3), 2015, pp.136-142. 9. Liu, D. Y., Jiang, H. F., Li, D. S., Zhao, B. Y., "Creep properties of rock under high confining pressure and high water pore pressure". Journal of Central South University (Science and Technology), 45(6), 2014, pp.1916-1923.
10. Gabriel, E. M., Cláudio, L. L. P., "New constitutive equation for salt rock creep", Rem: Revista Escola de Minas, 67(4), 2014, pp.397403.

11. Hakan, Ö., Lhsan, Ö., Sensogut, C., "Measurement and mathematical modeling of the creep behavior of Tuzkoy rock salt". International Journal of Rock Mechanics and Mining Sciences, 66, 2014, pp.128-135.

12. Xiong, L., X., Li, T., B., Yang, L. D., "Biaxial compression creep test on green-schist considering the effects of water content and anisotropy". KSCE Journal of Civil Engineering, 18(1), 2013, pp.103112.

13. Wang, J. B., Liu, X. R., Song, Z. P., Shao, Z. S., “An improved Maxwell creep model for salt rock". Geomechanics and Engineering, 9(4), 2015, pp.499-511.

14. Wang, J. B., Liu, X. R., Wang, T. H., "A nonlinear creep model for rocks based on modified fractional viscous body". Journal of Central South University (Science and Technology), 46(4), 2015, pp.1461-1467. 15. Zhang, Y., Xu, W. Y., Shao, J. F., Zhao, H. B., Wang, W., "Experimental investigation of creep behavior of clastic rock in Xingjiaba hydropower project". Water Science and Engineering, 8(1), 2015, pp.55-62.

16. Lu, Y. L., Elsworth, D., Wang, L. G., "A dual-scale approach to model time-dependent deformation, creep and fracturing of brittle rocks". Computers and Geotechnics, 60, 2014, pp.61-76.

17. Liu, L., Wang, G. M., Chen, J. H., Yang, S., "Creep experiment and rheological model of deep saturated rock". Transactions of Nonferrous Metals Society of China, 23(2), 2013, pp.478-483. 